\title{
Erratum for Manuscript "Study On Neutrophil Lymphocyte Ratio And Platelet Lymphocyte Ratio In COVID-19 From Our Prospective. A Cross Sectional Study."
} DOI:10.47799/pimr.0901.18

In the article entitled "Study on Neutrophil Lymphocyte ratio and Platelet lymphocyte ratio in COVID-19 from our prospective -A cross sectional study" published in the Volume 8, Issue 3, September- December 2020 issue of the Perspectives In Medical Research ,[1] the author's sequence and affiliation is incorrectly written. The correct sequence is as under.

1. Syed Imran Ali, Assistant Professor, Department of Physiology, Mamata Academy of Medical Sciences

2. Farha Tarannum, Assistant Professor, Department of Community medicine, Mamata Academy of Medical Sciences

3. Rubiya Khan, Assistant Professor, Department of Pathology, Mamata Academy of Medical Sciences

4. M Kanya Kumari, Professor, Department of Pathology, Mamata Academy of Medical Sciences

5. Mujahid Mohammed, Associate Professor, Department of Physiology, Mamata Academy of Medical Sciences

6. Mohammed Asghar Ali, Professor, Department of Physiology, Mamata Academy of Medical Sciences

Corresponding author: Syed Imran Ali, Assistant Professor, Department of Physiology, Mamata Academy of Medical Sciences

\section{REFERENCES}

1. Ali SI, Farah T, Khan R, Kanyakumar M, Mohammad M, Mohammad AA. Study on Neutrophil Lymphocyte ratio and Platelet lymphocyte ratio in COVID19 from our prospective. A cross sectional study.Perspectives in Medical Research 2020; 8 (3):56-59.

DOI: 10.47799/pimr.0803.18 